\title{
LET THE PUNISHMENT FIT THE VIEWER: UMA MASO-CRÍTICA DOS FILMES DE MARIA BEATTY
}

\author{
Ramayana Lira de Sousa \\ Alessandra Soares Brandão ${ }^{1}$
}

\begin{abstract}
Resumo: A pornografia tem sido tradicionalmente vista como uma das expressões mais perfeitas da opressão falocêntrica. Esta proposta busca desafiar essa percepção ao questionar a posição da espectadora lésbica diante dos filmes pornô de tintas masoquistas dirigidos pela americana Maria Beatty. Pensando o contrato masoquista a partir de Deleuze, queremos apontar nessas obras a desacelaração da imagem-movimento que resulta do trabalho do fetiche, de tal forma que a imagem pornográfica se aproxima da imagem-tempo. A economia sexual dos filmes de Beatty está menos relacionada às reminiscências pré-Édipo tão enfatizadas pelas teorias psicoanalíticas e mais à produção de máquinas desejantes que demandam uma fragmentação radical do corpo da espectadora. Com isso, procuramos mostrar como a pornografia pode se tornar um experimento criativo que, ao deslocar posições de espectatorialidade já consolidadas em clichês, nos apresenta imagens abertas, cruéis e necessárias.
\end{abstract}

Palavras-chave: Pornografia. Lesbianismo. Masoquismo.Imagem-tempo.

I do not read things; I read with things. When I read with theorists, with art, with a colleague or a friend, to read with is to cultivate a quality of attention to the disturbance of their alien epistemology, an experience of nonsovereignty that shakes my confidence in a way from which I have learned to derive pleasure, induce attachment and maintain curiosity about the enigmas and insecurities that I can also barely stand or comprehend. (Lauren Berlant, Sex, or the unbearable)

Poucas situações ombreiam a pornografia na capacidade de problematizar o olhar de quem investiga. Ainda mais porque, tradicionalmente, a obra pornográfica pouco escapa a perspectivas moralizantes. Como já lembrava Susan Sontag em "A imaginação Pornográfica" (1987), a pornografia costuma ser não apenas patologizada mas também colocada em um tribunal da má consciência, ensejando um debate que extrapola a peleja sobre predileções estéticas. A natureza do debate tradicional sobre o pornográfico é diferente, por exemplo, da discussão acerca do realismo bazaniano que tanto defende o plano sequência em detrimento da montagem. Se contra ou a favor do realismo baziniano não evoca as consequências de caráter policialesco e judicial que a defesa da pornografia carrega. Dito isso, assumimos desde já uma posição propositiva e positiva em relação à pornografia por acreditarmos que seus excessos, desvios e problemas nos ajudam a compreender modos de olhar e produzir imagens e a mapear espectatorialidades insuspeitadas. Assim procedendo, acreditamos estar defendendo não exatamente a pornografia, mas o próprio pensamento dos limites impostos pelo senso comum da normalidade e moralidade.

\footnotetext{
${ }^{1}$ Professoras do Programa de Pós-Graduação em Ciências da Linguagem da Universidade do Sul de Santa Catarina. E-mails: ramayana.lira@gmail.com e alessandra.b73@gmail.com.
} 
Nossa rota é a seguinte: baseando-nos na teorização de Gilles Deleuze (2009) sobre o contrato masoquista e sobre a temporalidade no cinema moderno, nós apontamos a encenação de cenas masoquistas lésbicas em filmes da cineasta estadunidense Maria Beatty que desaceleram a imagem-movimento e chegam a criar imagens-tempo. Procuraremos mostrar que a economia sexual dos filmes de Beatty se distancia do universo pré-edipiano descrito nas teorias psicanalíticas, pois o que tais filmes fazem é criar máquinas desejantes que demandam uma fragmentação radical do corpo da espectadora.

Além disso, argumentamos que o realismo que caracteriza a imagem pornográfica está relacionado às potências afetivas e cronogenéticas da performance - e da imagemtempo deleuziana - que complicam a diferenciação entre autenticidade e falsidade. Pensamos os filmes de Beatty como instâncias de um cinema do ritual do corpo, onde o corpo humano (e objetos), através do ritual, funciona de formas novas. A performance nesses filmes traz intensidades desestabilizadoras que desafiam o pensamento binário e geram uma temporalidade singular que não organiza as imagens de acordo com uma cronologia, mas que está constantemente reinventando o tempo.

Neste modelo que propomos, a espectadora masoquista é uma subjetividade que está por vir e a ser construída pela e na prática da espectatorialidade masoquista. Essa subjetividade-por-vir, condenada a adiar o prazer na expectativa pela dor, nos oferece uma valiosa lição crítica: ao encararmos uma fácil gratificação representacional com imagens de sexo, dor e violência, nós somos obrigadas a postergar o prazer e a desacelerar o julgamento moral. Dessa forma, queremos mostrar o quanto a pornografia é um experimento criativo que, ao deslocar posições bem definidas para a espectadora, nos apresenta imagens abertas, cruéis e necessárias.

Para entender o universo masoquista de Maria Beatty apostamos no desvio à teoria psicanalítica proposto por Gilles Deleuze. Em Sigmund Freud (1974 [1924]) nós temos o masoquismo fundado no drama edipiano. Para Freud, há dois pólos: o feminino/passivo e o masculino/ativo. Nesta arena, a figura paterna se constitui na grande ameaça ao filho, por ser o pai o portador do poder da castração e de inscrever a falta no filho, tornando-o, assim, uma mulher. A falta é tomada como algo comum na mulher, mas não no homem. Existe, assim, a possibilidade do medo da castração se desenvolver em perversão masoquista, na medida em que o medo leva o menino a assumir um papel passivo para aplacar o impulso castrador do pai e, assim, conquistar seu amor. Ser punido, espancado pelo pai, segundo Freud,

\footnotetext{
não é apenas o castigo pela relação genital proibida [com a mãe], mas também o substituto regressivo daquela relação, e dessa última fonte deriva a excitação libidinal que se liga à fantasia a partir de então, e que encontra escoamento em atos masturbatórios. Aqui temos, pela primeira vez, a essência do masoquismo. (1974 [1919], p. 235)
}

Deleuze propõe uma revisão dessa cena comentada por Freud. Começa por recusar a fusão freudiana entre sadismo e masoquismo, conferindo independência a esse último. Deleuze irá, então, retornar à fonte literária da qual deriva os termos em questão para apontar as diferenças irreconciliáveis entre a escrita de Leopold von SacherMasoch e o Marquês de Sade, não apenas em termos sexuais, mas também, e 
principalmente, em termos estilísticos e narrativos. Uma das principais marcas dessa diferença está no contrato masoquista desenvolvido nas obras de Sacher-Masoch. Em romances como A Vênus das peles, Sacher-Masoch aposta no caráter pedagógico da relação sexual. De acordo com Deleuze, estamos diante de uma vítima que procura uma algoz a quem precisa educar e persuadir de forma a concretizar suas estranhas fantasias. A subjetividade masoquista requer, pois, um contrato onde se estabelecem as regras, os papeis e as posições. O masoquista, podemos dizer, é um exímio meutteur-en-scène, um grande encenador que parte do contrato onde estão colocados história e personagens, ações e expectativas. O masoquismo é, ao mesmo tempo, teatro e realidade, performance que cria um mundo.

Deleuze afirma que é o contrato firmado com a mulher que constitui o elemento essencial do masoquismo. A relação funciona como uma ruptura entre desejo e prazer: se o prazer é uma interrupção no desejo, então o desejo precisa sempre postergar o prazer como condição mesma de sua existência. É essa constante tensão criada pela antecipação do prazer (sempre negado pela dor) que constitui o processo ininterrupto do desejo. O essencial no masoquismo é a espera, o suspense, que se manifesta como uma intensidade física e espiritual plena. Se uma relação sexual normativa se caracteriza pela finalidade do ato do gozo, alcançado através de uma série de ações e reações, a relação masoquista é marcada pela suspensão dessa finalidade, que se perde na expectativa gerada pelas normas do contrato.

Outra propriedade do masoquismo discutida por Deleuze diz respeito à relação entre o humano e o animal. Em Crítica e Clínica, Deleuze desafia a compreensão de que os personagens masoquistas, em suas cenas de submissão e regime de treinamento, imitariam animais. O contrato masoquista não estipula "faça como os animais", mas determina "faça comigo", entremos juntos em uma zona de indeterminação onde mulher e animal, animal e homem se tornam indiscerníveis (1997, p. 65).

Contudo, a despeito da relevante revisão proposta por Delueze, sua teorização do masoquismo apresenta um ponto cego; a figura da dominatrix. O próprio Deleuze admite que a mulher cruel não pode ser sádica porque está totalmente imersa na situação masoquista que, em última instância, é determinada pelo homem. São os personagens masculinos de Sacher-Masoch que desenham a máscara e dirigem a performance da dominatrix. Ou seja, em Deleuze a cena continua sendo heterossexual e a posição da mulher permanece como realização da fantasia masculina ${ }^{2}$. Contudo, como argumentamos mais adiante, o insight deleuziano sobre a temporalidade específicoa do desejo masoquista pode ser iluminador quando pensamos os filmes de Maria Beatty.

Nesse sentido, Lynda Hart (1998), fazendo a crítica de teóricos como Leo Bersani e Kaja Silverman, para quem a potência libertadora do masoquismo aparece como a sexualidade privilegiada para a produção de um "novo homem" (tanto gay quanto heterossexual), mostra como tais abordagens deixam intactas as construções psicanalíticas do masoquismo feminino onde aos homens é dado ter a experiência masoquista como perversão enquanto as mulheres continuam sendo vistas simplesmente como constitutivamente (ou essencialmente) masoquistas.

\footnotetext{
2 É interessante notar como a proposta deleuziana, nesse momento, parece ter os mesmos limites da teorização da espectatorialidade empreendida por Laura Mulvey em "Prazer visual e cinema narrativo".
} 
É aqui que gostaríamos de introduzir a diferença que o masoquismo lésbico pode trazer. Os filmes de Maria Beatty podem nos ajudar a pensar elementos que tornam mais complexas (e mais queer) as posições da espectadora (e da crítica). Beatty nasceu na Venezuela e se criou nos Estados Unidos, onde iniciou sua carreira como submissa satisfazendo uma clientela de homens heterossexuais. No início dos anos 1990, com uma bagagem artística que incluia performance, passou a dirigir curtas-metragem que tematizavam fantasias masoquistas lésbicas. Nesse sentido, Beatty foi uma das primeiras cineastas a se assumir como lésbica e masoquista e a investir nesse universo como expressão do desejo. Em entrevista ao site Mailfemale.tv ela revela que se interessou pelo cinema como forma de explorar a própria sexualidade e de, a partir da sua posição como submissa, poder ter controle sobre as fantasias do começo ao fim ${ }^{3}$. Ao contrário do mundo criado por Sacher-Masoch, nos filmes de Beatty a mulher cruel é dirigida a partir do desejo de outra mulher. $\mathrm{O}$ contrato masoquista em Beatty (nunca explicitado, é preciso que se diga) é estabelecido em termos mais iguais, de forma que a distribuição de poder é mais horizontal. Já há algum tempo Beatty deixa de participar diretamente das cenas e passa apenas a dirigir seus filmes. Esse movimento permitiu que, ao entrar em contato com outras performers, ela encontrasse a oportunidade de trazer as fantasias de outras mulheres para as obras, em um sentido de colaboração que enfatiza a transversalidade do desejo e dos poderes.

Beatty caracteriza seus filmes como erotic noir, híbridos que aglutinam qualidades do cinema propriamente erótico e sua exploração da sexualidade, e do cinema noir, principalmente na qualidade fotográfica das obras. Contudo o aspecto propriamente noir pode ser melhor percebido em filmes como The black glove, Let the punishment fit the child e Ladies of the night, com sua fotografia em preto e branco contrastada e personagens sombrios. Visualmente, o conjunto da obra remete, ainda, à ficção científica (Post Apocalypse Cowgirls), ao cinema mudo (The elegant spanking), ao cinema independente estadunidense (Skateboard kink freak), ou seja, há uma fluxo de referências cinematográficas que denotam um repertório cinéfilo.

Um desafio que o cinema de Beatty nos coloca é pensarmos em termos da construção da espectatorialidade quando nos deparamos com o ponto de vista da mulher submissa que é, também, a metteur-en-scène. Suas obras embaralham questões de gênero (cinematográfico e social) e sexualidade ao privilegiar o ponto de vista da submissa, perspectiva em geral ausente na pornografia BDSM. Essa ausência encontra analogia na inadequação de abordagens que apostam que a mulher dominante na relação sado/masô representa uma inversão das relações patriarcais e que isso deveria ser valorizado, enquanto as mulheres submissas apenas reiterariam o patriarcado. Rosalind Galt (2010) propõe que está na hora de revermos essa alegorização de relações de poder que nos dá, na verdade, um modelo limitador das políticas do desejo.

Interessa-nos pensar o desejo nos filmes de Beatty para além dos termos freudianos e alegorizantes. Para Freud a noção de desejo está relacionada a uma falta, ao desejo de possuir algo que complete uma falta. Em Deleuze temos o desejo como algo experimental, imprevisível e produtivo em si mesmo. Os filmes de Beatty articulam

\footnotetext{
${ }^{3}$ A expressão utilizada por Beatty é "I wanted to take charge from the bottom, topping from the bottom" (grifo nosso), indicando o trânsito de poder que há nas relações em seus filmes.
} 
essa vocação experimental do desejo nas inúmeras cenas que constrói, a cada vez produzindo uma nova máquina desejante. O desejo masoquista nos coloca um paradoxo: sendo a masoquista uma educadora (afinal, é ela quem determina os termos, limites e cenários da relação), ela parece não aprender a lição que a dor inflige, voltando sempre às situações doloridas. A masoquista parece viver em eterno esquecimento da dor anterior e em permanente expectativa da dor que virá. Marco Abel no ajuda a compreender a subjetividade masoquista não como um sujeito hegeliano que não aprende com seus erros, mas como produção política. Do masoquismo emana uma temporalidade singular baseada no fetiche que, de acordo com Deleuze, não tem valor simbólico, mas se apresenta como uma imagem congelada, uma fotografia à qual se retorna para exorcizar as consequências do movimento e que representa o último ponto no qual ainda é possível se acreditar (Sade-Masoch, p. 31). O universo de Beatty, composto por quadros onde cada cena se coloca em um espaço fechado, invariavelmente retoma fetiches, sejam sapatos, artigos de couro, brinquedos eróticos. Além disso, são várias os momentos de bondage, ou seja, o corpo mesmo é posto nessa desacelaração da imagem, amarrado a um estado de espera e cortando o circuito da ação/reação que caracteriza o movimento cotidiano.

Em The elegant spanking (1995) os crédito iniciais já estabelecem a noção de autoria partilhada entre a dominadora e a submissa, evidenciando a horizontalidade da relação de produção. Em seguida, a dominadora, interpretada ${ }^{4}$ por Rosemary Delain, dança em frente ao espelho, claramente satisfeita consigo mesma, equanto ao fundo, Kitty, a empregada doméstica interpretada por Maria Beatty, observa discretamente. Kitty delicadamente arruma o arranjo de rosas sobre a mesa, roubando, do espelho, imagens de sua patroa se masturbando. Os olhares são rápidos e marcam bem a construção do ponto de vista do filme: é através da submissa que se dá a focalização. São seus olhares e gestos que conduzem a câmera, é a sua espera que determina a temporalidade do filme. Além disso, intertítulos trazem fragmentos do fluxo do pensamento de Kitty, como "Será que ela pensa em mim? Acho que não". É essa focalização que permite a experiência da espera, não apenas na antecipação do próximo golpe ou na dilatação do tempo dos gestos, mas na repetição de situações, como a ingestão da urina da dominadora, reiterada pela edição, e que marca uma pausa na ação.

Assim, podemos entender o corpo masoquista como uma espécie de imagemcristal, agregando temporalidades diversas. O corpo masoquista lésbico coloca em questão, através de sua performance, não apenas as temporalidades teleológicas, mas, também, nos permite observar, em suas intensidades afetivas, o cinema não apenas como um teatro onde se representam fantasias, mas, antes de tudo, como um fábrica onde o desejo se produz. Elena Del Rio pressupõe essa capacidade afetiva do corpo em performance quando diz que

\footnotetext{
${ }^{4}$ É uma pena que percamos, em português, o jogo de palavras presente no verbo inglês to play, que significa interpretar e jogar. A cena sadomasoquista é, antes de tudo, um jogo do desejo, de maneira que as performances nos filmes imbricam em um mesmo gesto o distanciamento de um "interpretar" outra pessoa e a imersão do "jogar" com as regras e papeis.
} 
da concepção feminista psicanalítica [ela está se referindo à teorização de Laura Mulvey] da mulher como fetiche visual se segue que o corpo da performer é considerado um corpo exaustivamente escrito. Supostamente colonizado pela linguagem/discurso, desejo, fantasia do outro, o corpo da mulher raramente se vê capaz de escrever seu próprio significado ou de escapar momentaneamente da zona do significado explicável ${ }^{5}$ (p. 5).

Esse corpo masoquista que exala imagem-tempo é um corpo também do vidente na expectância da dor. A focalização centrada na submissa que caracteriza os filmes de Beatty abre espaço para a produção de novos significados, ou mesmo, como é comum à escrita masoquista discutida por Deleuze, para que a linguagem tartamudeie. Linda Williams, em Hard Core, aponta as dificuldades que os atos extremos de [sado]masoquismo trazem para a espectadora. Ela coloca uma questão ética: a violência sexual é uma representação ficcional ou uma realidade encenada? ("Is violence a ficcional depiction, or is it an enacted reality?" p. 201). No entanto, diante da potência cronogenética das imagens-tempo produzidas pela desaceleração da relação masoquista, o problema ético descrito (e criticado) por Williams perde sua força. O problema do realismo em filmes masoquistas lésbicos de Beatty vai além do apelo icônico de uma imagem cuja vocação é se parecer cada vez mais com o real pré-fílmico, de forma que atos extremos deveriam ser desvalorizados por mostrarem o real "real demais", sem oferecer uma interpretação dessa realidade (argumento baziniano). Mas vai, também, além da defesa posta por William para quem o hard core sadomasoquista envolve não apenas as últimas técnicas e parafernálias para atingir mais e melhores orgasmos, mas também uma clara confrontação com os pólos oscilantes de nossas identidades de gênero e o papel que o poder desempenha nelas (p. 228).

Se pensarmos como Giorgio Agamben (2007), podemos "considerar que o cinema entra numa zona de indiferença em que todos os gêneros tendem a coincidir; o documentário e a narração, a realidade e a ficção. Faz-se cinema a partir das imagens do cinema." A pornografia de Maria Beatty confunde mundo e filme, ou, antes, produz um mundo em forma de filme. Não é tanto a pretensa proximidade do real de vídeos amadores que proliferam na internet, ambientados em salas de estar emprestadas ou em dormitórios de universitários. Mas também não apresentam impulsos narrativos mais complexos. O que temos no contrato masoquista celebrado entre Beatty e as outras performers e entre o filme e a espectadora é uma aliança ética que nos chama à responsa/bilidade (termo traduzido a partir de response/ability, de Marco Abel).

Contudo, Agamben erra ao generalizar e dizer que o pornô faz "como se houvesse sempre o que ver, ainda e sempre imagens por detrás das imagens" (2007). A imagemtempo, desacelerada de Maria Beatty vai contra essa generalização. Se, no mundo, criamos canções e danças de guerra, de trabalho, de família, o sexo e o desejo introduzem síncopes nessas canções. O sexo e o desejo desorganizam modos de ser e abalam nossa soberania. É preciso uma subjetividade masoquista para desestabilizar o sujeito dentro e diante da tela, redistribuindo, assim, forças e linhas de fuga. Abandonar a ilusão de soberania. Assistir aos filmes de Maria Beatty como uma prática convulsa de abertura radical à espera do próximo golpe.

\footnotetext{
${ }^{5}$ From the feminist psychoanalytic conceptualization of the female per- former as visual fetish it follows that the performer's body is considered an exhaustively written body. Allegedly colonized by another's language/ discourse, another's desire, another's fantasy, the female performer's is rarely a body capable of partially writing its own meanings or of momentarily escaping the zone of explicable meaning. (Tradução nossa)
} 
ABEL, Marco. Violent affect: literature, cinema, and critique after representation. Lincoln: University of Nebraska Press, 2007.

AGAMBEN, Giorgio. O cinema de Guy Debord. Blog Intermídias. 17 jul 2007. Disponível em $<$ http://intermidias.blogspot.com.br/2007/07/o-cinema-de-guy-debord-de-giorgio.html >. Acesso em 23 set 2014

DELEUZE, Gilles. Sacher-Masoch: o frio e o cruel. Rio de Janeiro: Jorge Zahar, 2009

Crítica e clínica. São Paulo: Editora 34, 1997

DEL RIO, Elena. Deleuze and the cinemas of performance: powers of affection. Edimburgo: Edinburgh UP, 2008.

FREUD, Sigmund. (1919). Uma criança é espancada: uma contribuição ao estudo das perversões sexuais. In: Edição Standard Brasileira das Obras Completas de Sigmund Freud. Rio de Janeiro: Imago, 1976. v. 17

. (1924) O problema econômico do masoquismo. In: Edição Standard Brasileira das Obras Completas de Sigmund Freud. Rio de Janeiro: Imago, 1976. v. 19

GALT, Rosalind. Perverse aesthetics: Maria Beatty, masochism and the cinematic. World picture 4. Spring 2010. Disponível em <http://www.worldpicturejournal.com/WP_4/Galt.html>. Acesso em 23 set 2014

HART, Lynda. Between the body and the flesh: performing sadomasochism. Nova York: Columbia UP, 1998.

MULVEY, Laura. Prazer visual e cinema narrativo. In: XAVIER, Ismail. A experiência do cinema. Rio de Janeiro: Edições, Graal, 1983

SONTAG, Susan. A imaginação pornográfica. In: A vontade radical: estilos. São Paulo: Companhia das Letras, 1987

WILLIAMS, Linda. Hard core: power, pleasure, and the "frenzy of the visible". Berkley: University of California Press, 1999.

Recebido em 26/09/2014. Aprovado em 20/11/2014

Title: Let the punishment fit the viewer: masocriticism of Maria Beatty's films

Abstract: Pornography has traditionally been seen as one of the most perfect expressions of phallocentric oppression. This proposal aims at challenging this perception by questioning the lesbian spectator's position in relation to the masochistic films by American filmmaker Maria Beatty. Drawing from Deleuze's theorization of the masochistic contract and of temporality in modern cinema, we point out that the staging of masochistic scenes slows down the movement-image and eventually creates time-images. The sexual economy in Beatty's films, thus, distances itself from the pre-Oedipal universe described by psychoanalytical theories; what they do is create desiring machines that demand a radical fragmentation of the spectator's body. In the model we propose, the masochistic spectator is a subject that is yet to be constructed through and in the masochistic practice of viewing. This subject-to-come, bound to postpone pleasure in expectation of pain, has a valuable critical lesson to teach us: when facing easy representational gratification with images of sex and violence we are invited to delay pleasure, to slow down judgement. Therefore, we intend to show how pornography can be considered a creative experiment which, by displacing well-established positions for the spectator, presents us with open, cruel and necessary images.

Keywords: Pornography. Lesbianism. Masochism. Maria Beatty. 
